International Journal of Agriculture, Environment and Bioresearch

Vol. 4, No. 05; 2019

ISSN: $2456-8643$

\title{
POLLINATION EFFICIENCY OF Megachile bituberculata (HYMENOPTERA: MEGACHILIDAE) ON Cajanus cajan (Fabaceae) FLOWERS AT MAROUA- CAMEROON
}

\author{
Olivier Balti Moudelsia, Joseph Blaise Pando*and Denis Djonwangwé \\ Laboratory of Biological Sciences, University of Maroua, Higher Teachers' Training College, Maroua, Cameroon
}

http://doi.org/10.35410/IJAEB.2019.4441

\begin{abstract}
The studies were conducted in Maroua-Cameroon to assess the impact of Megachile bituberculata visit on the production of Cajanus cajan. Two treatments were used on each 50 randomly-selected plants. These included Autonomous Self-Pollination (ASP) with flowers from which insects visit, with airborne pollen flow excluded (treatments 1), flowers that received a single bee visit (SBV) of $M$. bituberculata (treatments 2). This bee mainly foraged for nectar and pollen resources. The mean foraging speed was 11.59 flowers/min $(n=39 ; \mathrm{s}=1.95)$ and the duration of visits was $10.65 \mathrm{~s}(\mathrm{n}=32 ; \mathrm{s}=4.07)$ to collect pollen and nectar. Megachile bituberculata is an effective pollinator, it shakes flowers and this movement could facilitate the liberation of pollen by anthers, for the optimal occupation of the stigma and of course their visits increase fruiting rate of $87.18 \%$, percentage of seeds/pod of $16.4 \%$, percentage of normal seed of $5.58 \%$ and percentage of weight seed of $19.35 \%$ in Maroua. Conservation of $M$. bituberculata nests close to pigeonpea farms can be recommended to increase pod and seed production in the region.
\end{abstract}

Keywords: Cajanus cajan, flowers, Megachile bituberculata, pollination, yields.

\section{INTRODUCTION}

Pigeonpea or (Cajanus cajan L. 1990) is one of the most important pulse crop in which flowers are self-fertilized with 20-40\% cross-fertilization (Pando et al., 2011). This is because 80-90\% anthers dehisce in bud stage and flowers are known to have pre-anthesis cleistogamy (Singh, 2016a). Its long stamens are utilized in insect aided out crossing and frequent visits of pollen carrying insects across various genotypes lead to natural cross pollination (Saxena, 2006). The large yellow flowers of pigeonpea attract various insect species, particularly bees (Pando et al., 2011; Singh, 2016a). The relationship between $C$. cajan and anthophilous insects have not been well studied in Cameroon. In other countries of World such as Kenya, Tanzania and India, Otieno et al. (2011), Martins (2013) and Ichpal et al. (2017) reported that Megachile bees manipulated the flower by landing on the keel and grappling with it in the process of seeking nectar and pollen. The studies by Pando (2013) have shown that Megachile bituberculata visits C. cajan flowers to harvest both nectar and pollen and increases its pollination. Previously no research survey reported on the pollination efficiency of $M$. bituberculata on $C$. cajan flowers in Cameroon. The size of Megachile (Ichpal et al., 2017) plays an important role in crop pollination. According to Otieno et al. (2011), when collecting nectar and/or pollen, it shakes 
flowers and this movement facilitates the liberation of pollen from anthers, for the optimal occupation of the stigma. This bee can be managed for pollination (Singh, 2016b). Also, Pando (2013) reported that pollen loads on the $M$. bituberculata were observed to be abundant and the ability of this bee to disperse swiftly across large areas suggests that it is able to cross pollinate the pigeonpea flowers regularly and efficiently. The present work is aimed at assessing the activity period, the foraging activity of $M$. bituberculata foragers on $C$. cajan and the effects of pollination efficiency of this bee on yields. The information recorded on the interaction of pigeonpea flowers and $M$. bituberculata will enable farmers to develop strategies that will increase the overall quality and quantity of pigeonpea yield.

\section{MATERIAL AND METHODS}

\section{Site and biological materials}

The study was carried out in Teving (Latitude $10^{\circ} 593$ '17' 'N, Longitude 14 204 '39' ' E and altitude $439 \mathrm{~m}$ ), a Western suburb of Maroua in the Far North Region of Cameroon, from June 2015 to February 2016. This site of study belongs to the ecological zone with three phytogeographical areas (Sahel-Sudanian, Sahelian and Sudanian altitude) periodically flooded, with unimodal rainfall (Letouzey, 1985). It has a Sahel-Sudanian climate type, characterized by two annual seasons: a long dry season (November to May) and a short rainy season (June to October); August is the wettest month of the year (Kuete et al., 1993). Annual rainfall varies from 400 to $1100 \mathrm{~mm}$ (Kuete et al., 1993). The annual average temperature varies between $29^{\circ} \mathrm{C}$ and $38^{\circ} \mathrm{C}$ and a daily temperature range between $6^{\circ} \mathrm{C}$ and $7{ }^{\circ} \mathrm{C}$ (Kuete et al., 1993). The experimental farm was an area of $588 \mathrm{~m}^{2}$. The animal material was represented by Megachile bituberculata naturally present in the environment. The surrounding vegetation of the farm was wild species and cultivated plants. The plant material used for our survey was the seeds of Cajanus cajan from IRAD Maroua.

\section{Planting and maintenance of culture}

On July $2^{\text {nd }} 2015$, the experimental farm that has been previously plowed was divided into six subs-plots of $10 \times 5 \mathrm{~m}^{2}$ each, with a row of two meters between the left and right subplots. This farm received seedlings of 6 lines per sub-plot. The seeds were sown in holes at the rate of 2 grains per hole. The spacing was $1 \mathrm{~m}$ between rows and $1 \mathrm{~m}$ on rows; a hole was $4 \mathrm{~cm}$ depth according to the technique from Niyonkuru (2002). Four weeks after germination (occurred August 4, 2015), the plants were thinned leaving the stronger. Thinning of the opening of the first flower, which occurred December first 2015, weeding was done with a hoe every three weeks. Weeding was performed manually as necessary to maintain weed-free plots. Direct observations on flowers were made daily during 14 days of the blooming period, between 7:00 and 11:00 am (local time) since preliminary observations indicated that pigeonpea flowers were fully visited by $M$. bituberculata between 6.00 am and $6.00 \mathrm{pm}$ (unpubl. data). At least, ten bee specimens were captured with the pliers and were conserved in a box containing $70 \%$ of ethanol for identification. Bee identification was done by Dr. Alain Pauly, Department of Entomology Royal Belgian Institute of Natural Sciences of Brussels in Belgium.

\section{Activity of Megachile bituberculata on Cajanus cajan flowers Floral products harvested}


The floral products (nectar or pollen) harvested by M. bituberculata during each floral visit were registered based on its foraging behavior. Nectar foragers were seen extending their proboscises to the base of the corolla while pollen gatherers scratched anthers with the mandibles or the legs. At the same time $M$. bituberculata encounter on flowers were registered, we noted the type of floral products collected by this bee. This parameter was measured to determine whether $M$. bituberculata was strictly gathering pollen, nectar or both, because this has implication for its efficacy as a cross-pollinator of $C$. cajan.

\section{Duration of visits and foraging speed}

During the registration of visits, the duration of the individual flower visits was recorded too (using a stopwatch) at least six periods: 7.00-8.00 hours, 9.00-10.00 hours, 11.00-12.00 hours, 13.00-14.00 hours, 15.00-16.00 hours and 17.00-18.00 hours. Moreover, the foraging speed, according to Jacob-Remacle (1989), is the number of flowers visited by a bee per min. According to Tchuenguem et al. (2014), the foraging speed can be calculated formulas follow: $V \mathrm{~b}=(F \mathrm{i} / d \mathrm{i}) \times 60$ (1) where $d \mathrm{i}$ is the time (s) given by a stopwatch and $F \mathrm{i}$ is the number of flowers visited during $d$ i.

\section{Assessment of the pollination efficiency of Megachile bituberculata on Cajanus cajan.}

To assess of the pollination efficiency of $M$. bituberculata, during the experimentation, two treatments were done:

- (1) Autonomous self-pollination (ASP) in which flower buds were isolated with hydrophilic bags (Figure 1) $\left(12 \times 16 \mathrm{~cm}\right.$; Osmolux ${ }^{\circledR}$, Pantek France, Montesson) a day before anthesis to prevent anthophilous insect visitation and airborne pollen flow the following day (treatments 1). These bags were removed the day following the anthesis.

- (2) Single bee visit (SBV) in which flower buds were isolated (Figure 2: treatment 2). Between 7.00 hours and 12.00 hours, the hydrophilic bags were delicately removed from each inflorescence carrying new opened flowers and this inflorescence is observed up to $20 \mathrm{~min}$ by four persons (observer team) positioned in the study field. The flowers visited by $M$. bituberculata were marked and the new opened flowers that were not visited were eliminated. Each flower was monitored until it received a single visit from $M$. bituberculata. After $M$. bituberculata visit, the flower was bagged with a hydrophilic plastic bag $(12 \times 16 \mathrm{~cm})$ until the next day to avoid any additional insect visit according to Vaissière et al., (1996) method, after which the flower and the equivalent plant were also tagged. At maturity, pods were harvested from each treatment and the number of seeds per pod was counted. The mean number of seeds per pod and the percentage of normal seeds (well-developed seeds) were calculated for each treatment. The fruiting rate due to the influence of $M$. bituberculata foraging $\left(F r_{\mathrm{i}}\right)$ was calculated as follow: $F r_{\mathrm{i}}=\left\{\left[\left(F r_{\mathrm{Y}}-F r_{\mathrm{X}}\right) / F r_{\mathrm{Y}}\right] \times 100\right\}$ (2), where $F r_{\mathrm{Y}}$ and $F r_{\mathrm{X}}$ are the fruiting rate in treatment $\mathrm{Y}$ (protected flowers and visited exclusively by $M$. bituberculata) and treatment $\mathrm{X}$ (protected flowers). $F r=\left[\left(F_{2} / F_{1}\right) \times 100\right]$ (3) where $F_{2}$ is the number of pods formed and $F_{1}$ the number of viable flowers initially set. The impact of $M$. bituberculata flowering on seed yields was evaluated using the same method as mentioned above for fruiting rate according to Tchuenguem et al., (2014) method. 


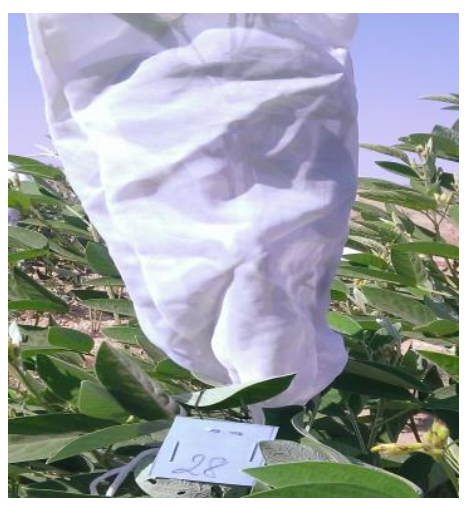

Figure 1: Bagged inflorescences (ASP) of Cajanus cajan

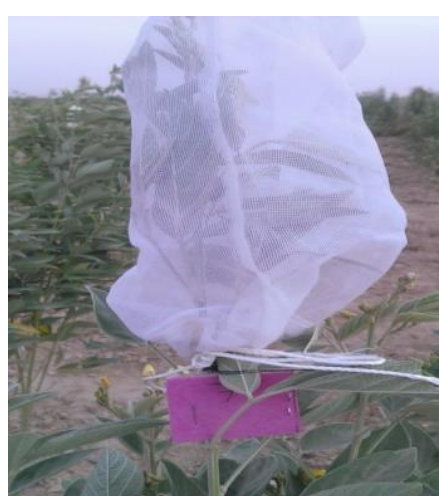

Figure 2: Bagged inflorescences (SVB) of Cajanus cajan

\section{Influence of neighboring floral}

During the survey period, flowers of several other plant species including: Hibicus rabdarifla (Malvaceae), Ipomea eriocarpa (Convulvulaceae), Commiphora africana (Burseaceae), Corchorus olitorius (Tiliaceae), Acacia senegalensis (Fabaceae) and Synedrella modiflora (Asteraceae) in vicinity bloom of the experimental plot were observed to attract $M$. bituberculata.

\section{Data analysis}

Data were analyzed using descriptive statistics, Student's t-test for the comparison of means of the two samples, chi-square $(\chi 2)$ for the comparison of two percentages using SPSS statistical software (version 19.0; SPSS, Inc. Chicago, Illinois, USA) and Microsoft Excel 2010.

\section{RESULTS AND DISCUSSION}

\section{Results}

\section{Activity of Megachile bituberculata on Cajanus cajan flowers}

From this study's field observations, $M$. bituberculata foragers are found to collect nectar and pollen on C. cajan flowers (Figure 3). The simultaneous collection of nectar and pollen is intensive and regular (more than $78.02 \%$ of visits). Other individual of M. bituberculata which are collecting either only nectar $(19.54 \%)$ or pollen $(02.44 \%)$ was very low. The activity of the Megachile bee observed foraging on pigeonpea flowers is mainly for pollen and nectar gathering base to their foraging behaviour. The mean duration of $M$. bituberculata visits per $C$. cajan flower varies significantly according to the type of food harvested. It is 10.65s $(n=32 ; s=$ $4.07)$, with a maximum of $24 \mathrm{~s}$ for nectar collected, against $3.26 \mathrm{~s}(n=32 ; s=2.02)$, with a maximum of $8 \mathrm{~s}$ for pollen collected. The difference between the duration of the visit for nectar and pollen collection is highly significant $(t=-23.18[d f=62, P<0.01]$. On the experimental plot of $C$. cajan, $M$. bituberculata visited between three and 15 flowers/min and the mean foraging speed was 11.59 flowers $/ \min (n=39 ; s=1.95)$. 


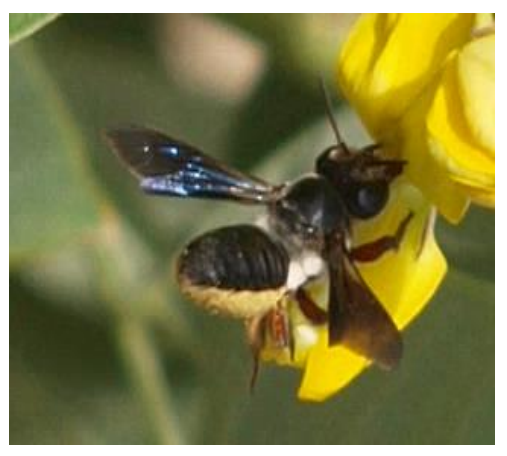

Figure 3: Megachile bituberculata foraging a Cajanus cajan flower

During the observation period, flowers of many other plant species growing near $C$. cajan were visited by M. bituberculata for nectar $(\mathrm{N})$ and/or pollen $(\mathrm{P})$. Among these plants were Hibicus rabdarifla (Malvaceae) N and P, Ipomea eriocarpa (Convulvulaceae) only P and Corchorus olitorius (Tiliaceae), only P. During a single foraging trip, an individual bee foraging on C. cajan was not observed moving from $C$. cajan to the neighbouring plant and vice versa.

\section{Pollination efficiency of Megachile bituberculata on Cajanus cajan}

During nectar and/or pollen collection from $C$. cajan, foraging $M$. bituberculata always shakes flowers and regularly induce contact with the anthers and stigma, increasing the possibility of cross-pollination of $C$. cajan. With this pollen, they flew frequently from flower to flower. The percentage of the total number of visits during which forager bees came into contact with the stigma of the visited flowers were $100.00 \%, 100.00 \%$ and $90.79 \%$ to harvest pollen and nectar, only pollen and only nectar respectively (Table 1 ). Thus, $M$. bituberculata greatly increased the pollination possibilities of $C$. cajan flowers.

Table 1: Number and frequency of contacts between Megachile bituberculata and the stigma during floral visits to Cajanus cajan

\begin{tabular}{|lccc|}
\hline Megachile bituberculata & & \multicolumn{2}{c|}{ Visits with stigmatic contacts } \\
\hline Products harvested & Number of studies visits & Number & Percentage \\
\hline Nectar & 152 & 138 & 90.79 \\
pollen & 19 & 19 & 100.00 \\
Pollen and nectar & 607 & 607 & 100.00 \\
\hline
\end{tabular}

Table 2 shows the fruiting rate, the mean number of seeds per pod, the percentage of normal seed and the percentage of seeds weight in treatments 1 (ASP) and treatments 2 (SBV). It appears from this table that each flower turned into a pod, regardless of the treatment it received.

(1) The fruiting rate ranged from $12.45 \%$ in treatment 1 to $97.14 \%$ in treatment 2 and the comparison of the fruiting rate showed that the difference observed was highly significant between treatments 1 and $2\left(\chi^{2}=488.96[d f=1 ; P<0.001]\right)$. Consequently, the fruiting rate of flowers bagged and visited exclusively by $M$. bituberculata (SBV) is higher than that of flowers 
bagged during their flowering period (ASP). The percentage of the fruiting rate due to $M$. bituberculata activity was $87.18 \%$.

(2) The mean numbers of seeds per pod were 2.09 and 2.50 in treatments 1 and 2 respectively and the difference was significant between treatments 1 and $2(t=-5.22[d f=204 ; P<0.05])$. Consequently, the number of seed yields per pod of flowers bagged and visited exclusively by $M$. bituberculata (SBV) is higher than that of flowers bagged during their flowering period (ASP). The contribution of $M$. bituberculata to the increment of the number of seeds per pod was $16.4 \%$.

(3) The percentage of normal seed was $84.55 \%$ and $89.55 \%$ in treatments 1 and 2 respectively and the difference between treatments 1 and $2(\chi 2=4.91[d f=1 ; P<0.05])$ was significant. Consequently, the percentage of normal seeds of floral access to only $M$. bituberculata (SBV) is higher than that of flowers bagged during their opening period (ASP). This may show high pollination deficit on the crop, indicating need for M. bituberculata management to increase developed seeds. The contribution of $M$. bituberculata to increase the percentage of normal seed was $5.58 \%$.

(4) The mean weight of seeds per pod was $0.36 \mathrm{mg}$ and $0.43 \mathrm{mg}$ in treatments 1 and 2 respectively, the difference between these mean was significant $(t=-5.33[d f=204 ; P<0.05)]$ and the percentage of weight seeds due to the foraging activity of insects was $19.35 \%$.

Table 2. Fruiting rate, percentage of normal seeds, mean seeds/pod, mean seed weight according to the treatments of Cajanus cajan

\begin{tabular}{|c|c|c|c|}
\hline Parameters & Treatment 1 (ASP) & Treatment 2 (SVB) & Comparison of treatments \\
\hline Fruiting rate $(\%)$ & 12.45 & 97.14 & $\chi_{*}^{2}=488.96[d f=1 ; P<0.01]$ \\
\hline$\%$ of normal seed $(\%)$ & 84.55 & 89.55 & $\chi^{2}=4.91[d f=1 ; P<0.05] *$ \\
\hline Seeds/pod & $\begin{array}{c}2.09(n=103 ; s= \\
1.01)\end{array}$ & $\begin{array}{c}2,50(n=103 ; s= \\
0.83)\end{array}$ & $\begin{array}{l}t=5.22[d f=204 ; P<0.05] \\
*\end{array}$ \\
\hline weight/pod & $\begin{array}{c}0.36(n=103 ; s= \\
0,17)\end{array}$ & $\begin{array}{c}0.43(n=103 ; s= \\
0.15)\end{array}$ & $t=5.33[d f=204 ; P<0.05] *$ \\
\hline
\end{tabular}

*: Significant at $\mathrm{P}<0.05$.

\section{Discussion}

This study indicates that $M$. bituberculata is visited pigeonpea flowers to collect nectar or/and pollen. The attractiveness of $C$. cajan nectar can be partially explained by its high sugar production and total sugar concentration (51-53\%: Pando, 2013), compared to range of 15-75\% in which most of the plant species fall (Proctor et al., 1996) and to inherent character such as colour of the flowers, presence of nectar guides on the flowers, availability of forage source (Ichpal et al., 2017). According to Pando et al. (2011) nectar produced by C. cajan attracts various insects in natural conditions.

The significant difference observed between the duration of pollen collecting visits and that of nectar collecting visits could be explained by the accessibility of each of these floral products. Floral morphology of this crop ensures high protection of the nectar such that the keel is forcefully opened and this ensures tripping of the flowers, resulting to pollen release. Under 
these conditions an individual bee must spend more time on flowers to obtain its nectar load, compared to the time it needs for pollen load. This result confirms other findings reported by Pando et al. (2011) in Yaoundé. The present study shows that during one foraging trip, an individual bee foraging on a given plant species scarcely visited another plant species. This result indicates that M. bituberculata shows flower constancy (Basualdo et al., 2000) for the flowers of each of the plant studied. Megachile bituberculata has been previously reported as good constancy visitor then effective pollinators (Pando, 2013; Abrol et al., 2015). Flower constancy is an important aspect in the management of pollination and this shows that M. bituberculata can provide advantages of pollination management for $C$. cajan. Investment in $M$. bituberculata management may provide high yield of this crop. During the collection of nectar and pollen on each flower, $M$. bituberculata regularly comes in contact with the stigma. It could enhance autopollination, which has been demonstrated in the past (Chaudhary and Jain, 1978; Pando, 2013; Singh, 2016b). Megachile bituberculata would provide allogamous pollination through carrying pollen within their furs, legs and mouth accessories, which is consequently deposited it to another flower of different plant belonging to the same species.

The positive and significant contribution of $M$. bituberculata in the pod, seeds yields and weight of $C$. cajan is justified by the action of this forager bee on self-pollination and cross-pollination. During foraging behaviour on flowers of pigeonpea, M. bituberculata plays a positive role: when collecting nectar and/or pollen, this bee shakes flowers and this movement could facilitate the liberation of pollen by anthers, for the optimal occupation of the stigma. Nevertheless, the morphology of pigeonpea flowers seems to avoid auto-pollination and seems to favour crosspollination (Otieno et al., 2011; Martins, 2013). Pollen grains of pigeonpea are heavy and sticky and could not be readily transferred by wind, therefore insects are responsible for transfer of pollen grains and consequently cross pollination in pigeonpea plant. Megachile bituberculata has been previously reported as good pollen collectors and effective pollinators (Tchuenguem et al., 2014; Ichpal et al., 2017). During our investigations, the falling of pollen carried by the foragers and the deposition of this pollen on the stigma and stamens of the flowers to be visited by the action of gravity and that of wind have been observed. Such pollen losses by bees are frequent at the end of single flower or inflorescence visits, especially during the hovering flight of foragers above these organs. The flowers that are exposed exclusively to $M$. bituberculata provided more pods, more seeds per pod with the heavier seeds and of better shape than the bagged flowers, in agreement to previous results reported by Pando et al. (2011) and Tchuenguem et al. (2014) on the same plant species. The higher productivity of floral access to only M. bituberculata visits compared with bagged flowers explains that insects' visits were effective in increasing cross pollination. Similar study, Pando et al. (2011) reported that pigeonpea (Cajanus cajan) shows pollination deficit even under normal circumstances, considering that flowers visited by Chalicodoma cincta cincta had higher yields compared to those under unlimited access by all visitors. The fruiting rate, the number of seeds/pod and the percentage of normal seeds of unprotected inflorescences were significantly higher than those of inflorescences protected from insects. Chalicodoma cincta cincta foraging resulted to a significant increment of the fruiting rate by $19.65 \%$, as well as the number of seeds/per pod by $24.33 \%$ and the percentage of normal seeds by $11.52 \%$. Conservation of $C$. c c cincta nests close to C. cajan fields could be recommended to improve pod and seeds production. 


\section{CONCLUSION}

Thus, it was observed that M. bituberculata enhance the productivity and pigeonpea provides forage source and help conserve this pollinator. This situation gives a possibility of $C$. cajan to benefit highly from pollination by this bee. The comparison of pods and seeds set of protected inflorescences with that of inflorescences visited exclusively by $M$. bituberculata underscores the value of this bee increasing pod and seed set as well as seed quality. This study shows the necessity of management of $M$. bituberculata in terms of nest provision at the proximity of $C$. cajan farm is worthy while for growers. Thus it is pertinent that growers provide congenial niche to conserve and enhance the increasing of native pollinators (Megachile and Chalicodoma) in pigeonpea to enhance productivity.

\section{ACKNOWLEDGEMENTS}

The authors thank the Institute of Agronomic Research for Development (IRAD -Maroua) for providing the seed, Dr Olivier Clovis Kengne (University of Maroua, Higher Teachers' Training College) for identification of plant species and Mr. Yves BEDI for their physical help during the study.

\section{REFERENCES}

Arem, (2011). Enjeux de la pollinisation pour la production agricole en Tarn-Et- Garonne. INP. Toulouse. p. 1-106.

Abrol D.P. and Shankar U. (2015). Role of Pollination in Pulses. Advances in Pollen Spore Research, 33: 101-103.

Basualdo M., Bedascarrasbure E., and De Jong D. (2000). Africanized honey bees (Hymenoptera: Apidae) have a greater fidelity to sunflowers than European bees. Journal of Economic Entomology, 93: 304-307.

Chaudhary J.P. and Jain J.L. (1978). Nesting and foraging behaviour of a mason bee Megachile lanata Lepel (Megachilidae: Hymenoptera). Indian Journal of Entomology, 40: 405-411.

Ichpal S., Shankar U., Abrol D.P. and Mondal A. (2017). Diversity of insect pollinators associated with pigeonpea, Cajanus cajan L. Mill sp. and their impact on crop production. International Journal of Current Microbiology and Applied Sciences 6 (9): 528-535.

Jacob - Remacle A. (1989). Comportement de butinage de l'abeille domestique et des Abeilles sauvages dans des vergers de pommiers en Belgique. Apidologie, 20 (4) : 271 - 285.

Kuete M., Melingui A., Mounkam J. and Nofiele D. (1993). Nouvelle géographie du Cameroun. EDICEF, Paris, p. 1-207.

Letouzey R. (1985). Notice de la carte phytogéographique du Cameroun au $1: 500$ 000. Institut de la Cartographie Internationale et de la Végétation, Toulouse, p. 1-142.

Martins D.J. (2007). Pollination Profile of Pigeon pea (Cajanus cajan) in Mwanza, Tanzania. Global Survey of Good Pollination Practices. Food and Agriculture Organization of the United Nations, Rome.

Martins D.J. (2008). Pigeon Pea (Cajanus cajan) in Mwanza, Western Tanzania. Initial Survey of Good Pollination Practices. Food and Agriculture Organization of the United Nations, Rome. 
Martins D.J. (2013). People, plants and pollinators: uniting conservation, food security, and sustainable agriculture in East Africa, In: Conservation Biology: Voices from the Tropics, 1st edn. Ed Sodhi NS, Gibson L, Raven PH. John Wiley and Sons Ltd, New York, p. 233238.

Niyonkuru D.N. (2002). La culture du pois cajan, un trésor méconnu en Afrique centrale. Editions Said Collection Experiences des Federations, p. 1-23.

Otieno M. (2013). Functional responses of bee communities to local management and landscape structure in pigeon pea cropping system in Kenya. In New Frontiers in Tropical Biology: The Next 50 Years. (A Joint Meeting of ATBC and OTS). The Association for Tropical Biology and Conservation (ATBC), 2013.

Otieno M., Woodcock B.A., Wilby A., Vogiatzakis I.N., Mauchline A.L., Gikungu M.W. and Potts S.G. (2011). Local management and landscape drivers of pollination and biological control services in a Kenyan agroecosystem. Biological Conservation 144: 2424-2431.

Pando J.B. (2013). Activité de butinage et de pollinisation de Apis mellifera, Chalicodoma cincta cincta et Xylocopa olivacea sur les fleurs de Cajanus cajan, Phaseolus coccineus et Vigna unguiculata à Yaoundé (Cameroun). Thèse de Doctorat/PhD., Université de Yaoundé I, Cameroun, p. 1-210.

Pando J.B., Tchuenguem F.F.-N. and Tamesse J.L. (2011). Pollination and yield responses of pigeon pea (Cajanus cajan L. Millsp.) to the foraging activity of Chalicodoma cincta cincta (Hymenoptera: Megachilidae) in Yaounde' (Cameroon). Journal of Animal and Plant Science 11: 1346-1357.

Proctor M., Yeo P. and Lack A. (1996). The natural history of pollination. In: Corbet SA, Walters SM, Richard W, Streeter D, Ractliffe DA. Ed Harper Collins, Harper Collins, London, p. 1-462.

Saxena K.B. (2006). Seed Production Systems in Pigeonpea. Patancheru, Andhra Pradesh, India: International Crops Research Institute for the Semi-Arid Tropics.

Singh A.K. (2016a). Insect pollinators and productivity of pigeonpea, Indian Journal of Entomology, 78: 163-166.

Singh A.K. (2016b). Pollinating Efficiency of Native Bee Pollinators of Pigeonpea (Cajanus cajan) in Nagaland. Russian Journal of Ecology, 47(3): 310-314.

Tchuenguem F.F.-N., Pando J.B. and Tamesse J.L. (2014). Pollination efficiency of Xylocopa olivacea (Hymenoptera: Apidae) on Cajanus cajan (Fabraceae) flowers at Yaounde, Cameroon. International Journal of Tropical Insect Science 33: 138-148.

Vaissière B.E., Rodet G., Cousin M., Botella L. and Torré Grossa J.P. (1996). Pollination effectiveness of honey bees (Hymenoptera: Apidae) in a Kiwifruit orchard. Journal of Economic Entomology, 89 (2): 453-461. 